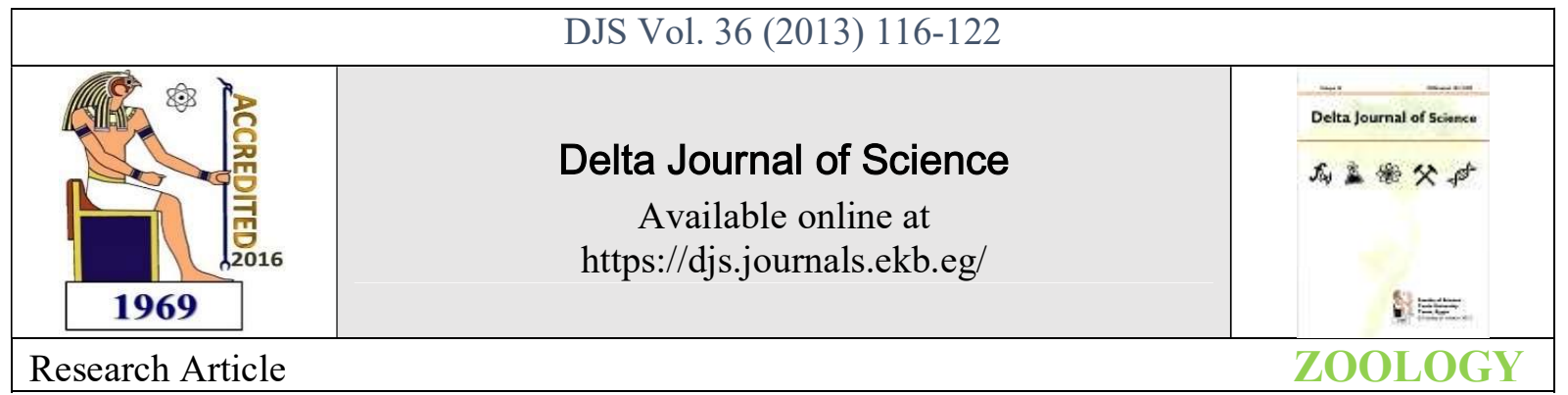

\title{
Role of the larval parasitoid, Bracon hebetor (Say) (Hymenoptera: Braconidae) in the control of Cadra (Ephestia) cautella and Plodia interpunctella (Lepidoptera: Pyralidae) in Egypt
}

\author{
Khalafalla Saber Ahmed \\ Biology Dept, Faculty of Education, Ain shams Univ, Cairo, Egypt
}

\begin{abstract}
The larval ectoparasitoid, Bracon hebetor was recorded for the first time from Cadra (Ephestia) cautella, a harmful pest of date crop in Egypt. The objective of this study was to investigate the biological control value of $B$. hebetor against the stored product pests $C$. cautella and $P$. interpunctella at controlled temperatures of $15,20,25$ and $30^{\circ} \mathrm{C}$ and relative humidity of $60 \%$ $\mathrm{RH}$. At $25^{\circ} \mathrm{C}$, the pre-oviposition, the ovposition and the post-oviposition periods of mated female $B$. hebetor were $0.75,41.25$ and 3.0 days. The daily number of eggs laid per female was 7.97 at $25^{\circ} \mathrm{C}$. The females lived longer than males at the 4 tested temperatures. The mean longevity of males under fed honey, host body fluid or water and nothing were 7.7, 7.2, 4.5 and 5.4 days, respectively. The durations of different developmental stages reared on C. cautella were slightly shorter than those on P. interpunctella. The total number of eggs, the durations of developmental stages, life span, and longevity were affected significantly by temperatures. Reproduction performance, host-parasite relationship and sex ratio of the parasitoid were also discussed.
\end{abstract}

Key Words: Parasitoid, Bracon hebetor, pests, Cadra Cautella, Plodia interpunctella

\section{INTRODUCTION}

Date palms and corn are among the most important horticultural crops in Egypt. Five million fruitful date palms are grown over the Nile Valley and Delta. Baharia Oasis is one of the most important regions in Egypt as it contains a large amount of wild and cultivated palm trees. Dates are considered as one of the main food source for Egyptian Oasis communities. Gross damage to date is made by larvae of Cadra cautella.

Cadra cautella (Walker) is one of the most important pest of harvested dates in Dakhlah and kharga Oasis (Gough, 1918). It causes damage to date crop by making holes, consuming large part, leaving feces or die within dates which minimizes the economic value of the product. In 1958, Martin found that E. cautella was a damaging pest of dates in Libya. The morphology of $C$. cautella was studied (Hammad et al. (1965). El-Saeedy (1981) studied the effect of sorted diets on development of C.. cautellla.

Bracon (Microbracon) hebetor (Say, 1836) is a cosmopolitan ectoparasitoid of several lepidopteran larvae. It is currently used a potential biological control agent against pyralid and stored grain pests. For instance it is used agaist Chloidea sp on chick pea in Iran (Noori, 1994), Plodia interpunctella Hubn. in USA (Brower and Press, 1990; Guertin et al., 1996) and
Galeria melonella (L.) in Turky (Gul and Guled, 1995a). B. hebetor significantly reduced Cadra cautella infestations in and around commercially packaged raisin in USA (Cline and Press, 1990). B. Hebetor female paralyzes its host by injecting venom into haemocoel. Drenth (1969) reported that only lepidopteran species are susceptible to its venom. Abbas and Abou-Zeid (1983) studied the biology of Bracon instabilis March (Hymenoptera: Braconidae), a larval parasite of Phthorimaea operculella Zell in Egypt

$B$. hebetor merits investigation as a control agent of the date pest $E$. cautella and the stored grain pest the Indian corn moth $P$. interpunctella.

\section{Materials and Methods}

C. cautella was initially obtained from infested dates collected from Aswan Governorate in 2010. B. hebetor was obtained as cocooned pupae form dates infested with $C$. cautella collected from Abo-Rawash area, Giza Governorate. Samples were kept in the laboratory until adult parasitoid emergence. Samples of both hosts and parasitoid were kindly identified by Dr. Papp of the British Museum in London. Laboratory colony of $C$. cautella was kept maintained on soft dates for several generations at $25+2 \mathrm{oC}$ and $60+5 \% \mathrm{RH}$. 
B. hebetor development was studied using $C$. cautella and $P$. interpunctella as hosts at different constant temperatures. All experiments were conducted at constant relative humidity following the method of Solomon (1951). Laboratory colony of $P$. interpunctella was maintained on granulated corn. Adult of both hosts were provided with drops of diluted bee honey. Adult parasitoid was kept and maintained in glass vials $(2.5 \times 9 \mathrm{~cm})$ covered with muslin cloth fitted in by rubber bands and where fed on pure bee honey or on haemolymph oozed from punctured larval bodies. Tests were carried by introducing one mated parasitoid female into a tube containing one host larva for 24 hrs then the larva was removed and replaced by a fresh one, throughout its life time. Parasitized larvae were kept separately in Petri -dishes until emergence of new adult parasitoids. Duration of larval instars was recorded at different temperatures. Dimensions of immature stages were measured using micro-slide micrometer. Behavior studies such as mating behavior and host seeking activities were studied by locating virgin, young, and aged parasitoid females searching for host larvae. Results are presented as means $+\mathrm{SE}$.

\section{RESULTS}

\section{Life cycle}

$B$. hebetor adult females emerged few hours before males. This is different from other hymenopteran parasitoids such as Scleroderma ephipium (Ahmed 1989). Mated females lay their eggs immediately after mating at 25 and $30 \mathrm{oC}$. Incubation period varied at different temperatures.

At $30 \circ \mathrm{o}$, on C. cautella, B. hebetor eggs hatched after $1.24+0.23$ days (range 0.5 -2.0 days). The incubation period increased to $3.06+0.22$ days (2.0-4.0 days) at $150 \mathrm{o}$ (Table 2 ). The hatched larvae molted 3 times giving 4 instars. The measurements and durations of larval instars are summarized in Table 1 and Figs 1-4. Full grown parasitoid larvae stop feeding and start spinning their cocoons. The average length of cocoons was $2.96+0.21 \mathrm{~mm}$ long while the width was $0.98+0.06 \mathrm{~mm}$. The cocoons were noticed on the surface and around consumed host larvae. They soon change to pre-pupae. Free pupae become darker gradually and emerge as adults. The duration of the different developmental stages were shorter at higher temperatures. The longest life cycle was $29.1+3.25$ days (24-32 range) at $15 \mathrm{oC}$, while the shortest was at $30 \mathrm{oC}(11.1+1.71$ days) (Table 2$)$. On the Indaian meal moth, $P$. interpunctella, the durations of the developmental stages were similar to those $B$. hebetor was close to those reported when the parasitoid was reared on $C$. cautella (Table 3).

\section{Parasitoid longevity:}

Effect of temperature:The longevities of adult female $B$. hebetor were $77.71+2.76,59.57+2.81,43.80+2.57$ and $17.83+1.33$ days at $15,20,26$ and $30 \mathrm{oC}$ and for males were $28.76+4.91,11.43+1.66,7.57+1.24$ and $4.73+1.63$ days, respectively. In general females lived longer than males at all tested temperature when provided with bee honey (Table, 4).

Effect of diet: The longevity of $B$. hebetor female was estimated at $25 \mathrm{oC}$ and $60 \%$ R.H. when provided variable foods. The longevities of females were $43.80+2.56,7.30+0.48$ and $6.30+1.5$ when fed on honey, water alone, host-body haemolymph, respectively. Meanwile males lived for $7.70+0.82,7.20+0.42$ and $4.5+0.70$ days, respectively. Females and males offered nothing lived only for $5.4+0.7$ and $4.8+0.79$ days for female and male, respectively, probably due to starvation. Data presented herein differed from those obtained when the parasitoid reared on G. melonella, the parasitoid longevities were 13.3 and 10.2 days for males and females at 25oC, respectively (Gul and Gulel, 1995a).The longer life span of those reared on $C$. cautella is probably due to the better chance of soft texture and availability of food.

\section{Mating behavior}

Six to ten hours after emergence, males chase females with their antennae in a $\mathrm{V}$ position, flap their wings, stop facing female then copulate for 15 to 60 seconds. It was recorded that the rate of copulation increased in the presence of host larvae. In rare cases, males mated with females immediately after emergence, but in all these cases eggs produced by these females either un-hatched or only produced males. Old females may respond from first time but virgins do that after 2-4 times. In case of presence of many female and one male only, females stand with antennae horizontal making several telescopic abdominal movements, presumably to prepare themselves to copulation and or produce sexual pheromone for attracting males. $B$. hebetor female mates with one male for 3-5 times within the first hour emergence. A female may mate with more than one male. In some cases a female may mate with 30 different males. Females do not mate with their own progeny, males only chase and mount the females.

\section{Oviposition and fecundity}

On C. cautella: Although female B. hebetor parasitoid attacks host larvae on dorsal position, most eggs were laid on the ventral side of the host larva. Eggs were hidden by fine setae. Smooth thin skin of the host larva facilitates hatched parasitoid larvae to puncture. When the ventral side was full, egg deposition started on the dorsal side. Eggs were laid in groups of four, as the female ovary contains 4 ovarioles only. Temperature significantly affected pre- and post oviposition periods. At $30 \mathrm{oC}$, a mated parasitoid female lay eggs immediately. At $15 \mathrm{oC}$, pre-, oviposition and post-oviposition periods were longest (Table 5). At $20 \mathrm{oC}$ and $25 \mathrm{oC}$, these periods were reduced to 1.75 and 0.75 days, respectively. The average number of eggs laid per female was $7.1+1.32$ eggs (range 6-8 eggs) daily at $25 \mathrm{oC}$. The fecundity of the female was affected by temperature. In addition the oviposition period was reduced from $41.25+1.5$ days (range 40-43 days) at $25 \mathrm{oC}$ to $18.0+0.81$ days (range $17-19$ days) at $30 \mathrm{oC}$. However the increase of temperature shortened the female life span. The total number of eggs laid increased with the high fecundity rate. The total numbers of eggs per female were 122.0+5.79, $300.25+11.14,327.5+4.72$ and $253.0+9.01$ eggs at 15,20 , 25 and $30 \mathrm{oC}$, respectively (Table 5 ).

On $P$. interpuncella: The fecundity of female $B$. hebetor was reduced when reared on $P$. interpunctella host as it lays only $3.2+0.23$ eggs/day (range $3-4$ eggs). This may be explained by the smaller size of $P$. interpunctella than C.cautella. Also eggs were laid only on ventral region of $P$. interpunctella presumably because that side is much smoother than dorsal one. Female $B$. hebetor synchronize itself with the type of host; availability of food texture of host body. Ohh (1993) reported that B. hebetor female lays 12.6 eggs/day on Ephestia ellutella, while only 3.5 eggs of Paralipsa gularis larva.

\section{Host-parasite relationships:}

Female $B$. hebetor anesthetizes its victim by stinging the host larva in the thin cuticle of the pleural side. As the female walks slowly until precedes the host larva, then stands with the abdomen bent forward and the ovipositor is prepared for stinging which occurs always in the opposite direction of host 
movement. After stinging, the stung larva moves only for few centimeters. In few cases larvae were stung 1-3 times. In the presence of more than host larvae available, the female parasite is completely busy anesthetizing all larvae first before presuming oviposition. Immediately after host paralysis, female Bracon starts egg laying from thoracic sterna backwards. On Cadra, the female lays 6-8 eggs larva/day at $25 \mathrm{oC}$, meanwhile only 1-3 eggs/larva/day were laid at $15 \mathrm{oC}$. If the host was left unchanged to the next day, female resumes laying eggs on the same host larva. Many females may destroy their eggs or embryos accidently during egg laying. When the females were deprived from hosts, they retain their eggs until the moment they find a host larva where they immediately lay their eggs.

Under heavy cases of super-parasitism (over 12 parasitoid/larva), cannibalism is observed. Females may lay eggs on already parasitized hosts causing the killing of already existed eggs or embryos. To avoid cannibalism among its progeny, a female may destroy few eggs. Emerged males and females are rather smaller sized compared to fewer number progeny, presumably due to scarcity of food in the former case. Reduction of hatchability of $B$. hebetor was reported as females may commit ovicide by killing their eggs using ovipositors (Antolin, et al., 1995). In laboratory cultures maintained in stock container of infested dates, collected from the field with adult male and female parasitoids, always males were on surface of dates while females were busy in the bottom looking for hosts.

\section{Sex ratio:}

The sex ratio of field collected $B$. hebetor was male bias. From 30 parasitized $C$. cautella larvae collected from date, the sex ratio was 1:3 (162 males : 59 females). When the same number of $C$. cautella larvae were exposed to $B$. hebetor in the laboratory, the sex ratio was female biases 1:3.9 (399 females to 109 males). Old females ( 3 weeks old) produced progeny of males even when males occurred with females all the time. Similar results were recorded when Ephestia kuehniella (Zeller) was used as a host (Rotary and Gerling, 1972). Fuester et al. (2003) reported similar results for the braconid wasp Glypapantales flavicoxi. The male biased sex ration may be the result of a variety of factors, including sperm depletion, sperm death, physiological aging, active sperm digestion by the female, sperm disintegration while stored in the spermathecae, the number of copulations and the differential mortality of the sexes during larval development (Uckan and Gulel, 2002; Damiens et al., 2003; Fuester et al., 2003; Gunduz and Gulel, 2005).

Under heavy super-parasitism, the sex ratio was male biased than female biased. The sex ratio changed with the time to male bias. This is might be due to cannibalism under crowded conditions. When eggs were taken from the same female and transferred to another host larvae, the sex ratio of the progeny was female bias. A similar result was obtained in Galeria sp parasitized by $B$. hebetor (Gul and Guel, 1995b).

\section{References}

Abbas, M.S.T. and Abou-Zeid, N.A. (1983). Biological studies on Bracon instabilis March (Hym., Braconidae) a larval parasite of Phthorimaea operculella Zell. (Lep., Gelechiidae) in Egypt. Z., ang. Ent., 96:32-36.

Ahmed, K.S. (1989). Biological and morphological aspects of the parasitoid, Scleroderma ephipium Saunders
(Hymenoptera: Bethylidae). Bull. Soc. Entomol. Egypte, 68: 307-320.

Antolin, M.F. Ode, P.J. and Strand, M.R. (1995). Variable sex ratio and ovicide in outbreading parasitic wasp. Animal Behavior, 49(3): 584-600.

Brower, J. H. and Press, J.W. (1990). Introduction of Bracon hebetor (Hymenoptera: Braconidae) and Trichogramma pretiosum (Hym.: Trichogramidae) in suppressing stored product moth population in small inshell peanut storage. J. Econ. Entomol., 83 (3): 1096 - 1101.

Cline L.D. and Press, J.W. (1990). Reduction in almond moth (Lepidoptera: Pyralidae) infestation using commercial packging of food in combination with the parasitic wasp, Bracon hebetor (Hymenoptera: Braconidae) J. Econ. Entomol., 83(3): 1110-1113.

Damiens, D., Breasac, C. and Chevrier, C. (2003). The effect of age on sperm stock and egg laying in the parasitoid wasp, Dinarmus basalis. J. Insect Sci. 3:22.

Drenth, D. (1969). Some aspects of the collection and the action of the venom of Microbracon hebetor Say. Acta Physiol. Pharmac. Neerl., 15:100-103.

EL-Saeedy, A.A. (1981) Ecological studies on Ephestia cautella (Walker). Zagazig Univ. Res. Bull. No. 309.

Fuester, R.W., Swan, K.S., Dunning, K. Taylor, P.B. and Ramaseshiah, G. (2003). Male-based sex ratios in Glyptaptapantalis faviocoxis (Hymenoptera: Braconidae) a parasitoid of the Gypsy moth (Lepidoptera: Lymantriidae). Ann. Entomol. Soc. Am., 96: 553- 559.

Gough, L.H. (1918). Notes on Ephestia, an insect injurious stored dates in Kharga Oasis. Bul. Soc. Entomol. Egypt., 5: $133-140$.

Guertin, D. S. Ode, P.J. Strand, M.R. and Antolin , M. F. (1996) Host searching and mating in an out breading parasitoid wasp. Ecological Entomol., 21 (1): 27-33.

Gul, M. and Gulel, A. (1995a). Biology of parasitoid Bracon hebetor (Say) (Hymenoptera: Braconidae) and the effect of host larvae size on fecundity and sex ratio. Turk. J. Zool., 19 (3): 231- 235.

Gul, M. and Gulel, A. (1995b). Effect of super-parasitism, in the parasitoid Bracon hebetor (Say), on fecundity and sex ratio. Turk. J. Zool., 19 (3): 237-240.

Gunduz, E.A. and Gulel, A. (2005) Investigation of fecundity and sex ratio in the parasitoid Bracon hebetor Say (Hymenoptera: Braconidae) in relation to parasitoid age. Turk. J. Zool., 29: 291-294.

Hammad, M.H., Al-Deeb, A. and Abd-El-Wahed, A. (1965). Studies on the date

moths in the UAR. The external morphology and biology of Ephestia cautella (Walker). Alex. J. Agric. Res., 14: 161-171.

Martin, H.E. (1958). Pests and diseases of date palm in Libya. FAO Plant Protect. Bull., 6: 120-123.

Noori, P. (1994). The parasitism of the wasp Habrobracon hebetor Say on Chloridia spp in check pea of Kermanshah Province. Appl. Entomol. Phyto1. Pathol., 61(1\&2):14-15 Ar 23-3

Ohh, M.H. (1993). Studies on biological characteristics of parasitic Hymenoptera, Bracon hebetor (Say) (Braconidae; Hymenoptera). Korean J. Entomol., 23 (3):143-149. 
Rotary, N. and Gerling, D. (1972) The influence of some external factors upon the sex ratio of Bracon hebetor (Hymenoptera: Braconidae). Environ. Entomol., 2 (1): 134138.

Solomon, M.E. (1951). Control humidity with potassium hydroxide, sulphuric acid or other solutions. Bull. Ent. Res. XIII (3): 543-554.

Uckan, F. and Guell, A. (2002). Age related fecundity and sex ratio variation in Apanteles galeriae (Hym.: Braconidae)and host effect on fecundity and sex ratio of its hyperparasitoid Dibrachys bormiae (Hymenoptera), J. Appl. Ent. 126: 534537.
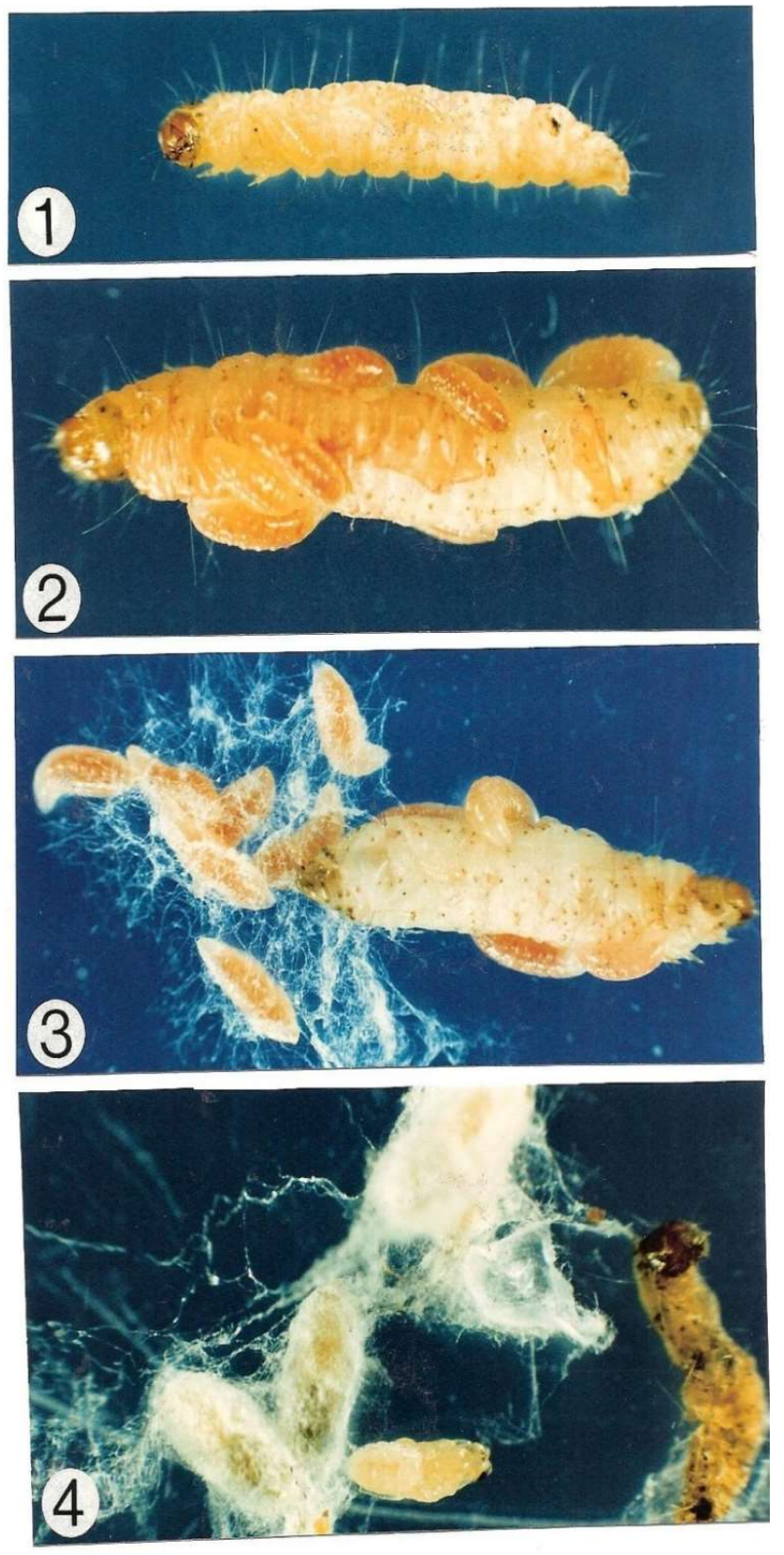

Figs. 1-4: Photographs of Bracon hebetor immature stages parasitizing larvae of C. cautellla., 1. 1st instar larva, 2. 2. Full grown parasitoid larvae, 3. Parasitoid pre-pupa and 4. Parasitoid pupa inside cocoon (one removed from cocoon). 
Table 1. Dimensions $(\mathrm{mm}+\mathrm{SE})$ of immature stages of Bracon hebetor reared on Cadra cautella at $250 \mathrm{C}$ and $60 \%$ RH.

\begin{tabular}{|r||c||c||c||c||}
\hline Stage & Body length & Body width & Mandible L & Mandible W \\
\hline \hline Egg & $0.39 \pm 0.06$ & $0.14 \pm 0.02$ & - & - \\
& $(0.3-0.50)$ & $(0.11-0.17)$ & & \\
\hline \hline $1^{\text {st }}$ larva & $0.61 \pm 0.04$ & $0.44 \pm 0.04$ & $0.042 \pm 0.055$ & $0.0146 \pm 0.002$ \\
& $(0.54-0.70)$ & $(0.37-0.50)$ & $(0.03-0.044)$ & $(0.01-0.02)$ \\
\hline \hline $2^{\text {nd }}$ larva & $1.09 \pm 0.07$ & $0.54 \pm 0.03$ & $0.13 \pm 0.023$ & $0.07 \pm 0.01$ \\
& $(0.98-1.20)$ & $(0.50-0.59)$ & $(0.10-0.17)$ & $(0.06-0.09)$ \\
\hline \hline $3^{\text {rd }}$ larva & $2.42 \pm 0.28$ & $0.82 \pm 0.05$ & $0.23 \pm 0.016$ & $0.13 \pm 0.014$ \\
& $(1.98-2.80)$ & $(0.76-0.95)$ & $(0.20-0.26)$ & $(0.11-0.17)$ \\
\hline \hline $4^{\text {th }}$ larva & $2.67 \pm 0.36$ & $0.91 \pm 0.09$ & $0.51 \pm 0.04$ & $0.25 \pm 0.03$ \\
& $(2.0-2.86)$ & $(0.80-1.00)$ & $(0.43-0.56)$ & $(0.20-0.30)$ \\
\hline \hline Pre-pupa & $2.74 \pm 0.06$ & $1.22 \pm 0.10$ & & - \\
& $(2.63-2.85)$ & $(1.00-1.32)$ & & - \\
\hline \hline Pupa & $2.66 \pm 0.12$ & $0.93 \pm 0.07$ & & - \\
& $(2.52-2.82)$ & $(0.80-1.00)$ & & \\
\hline \hline
\end{tabular}

Table 2. Duration (days $+\mathrm{SE}$ ) of immature stages and the total life cycle of Bracon hebetor reared on Cadra cautella at different temperatures.

\begin{tabular}{|c|c|c|c|c|}
\hline $\begin{array}{l}\text { Ten } \\
\text { Stage }\end{array}$ & $15^{\circ} \mathrm{C}$ & $20^{\circ} \mathrm{C}$ & $25^{\circ} \mathrm{C}$ & $30^{\circ} \mathrm{C}$ \\
\hline Inc. period & $\begin{array}{c}3.06 \pm 0.22 \\
(2-4)\end{array}$ & $\begin{array}{c}2.07 \pm 0.34 \\
(2-3)\end{array}$ & $\begin{array}{c}1.69 \pm 0.27 \\
(1.5-2.0)\end{array}$ & $\begin{array}{c}1.24 \pm 0.23 \\
(0.5-1.5)\end{array}$ \\
\hline $1^{\text {st }} 1$. larva & $\begin{array}{c}2.33 \pm 0.12 \\
(2-3)\end{array}$ & $\begin{array}{c}1.20 \pm 0.24 \\
(1-1.5)\end{array}$ & $\begin{array}{l}1.1 \pm 0.11 \\
(1.0-1.2)\end{array}$ & $\begin{array}{c}0.86 \pm 0.16 \\
(0.5-1.0)\end{array}$ \\
\hline $2^{\text {nd }}$ 1. larva & $\begin{array}{c}3.07 \pm 0.70 \\
(3-4)\end{array}$ & $\begin{array}{c}2.27 \pm 0.66 \\
(2.5-3)\end{array}$ & $\begin{array}{c}2.11 \pm 0.79 \\
(2-3)\end{array}$ & $\begin{array}{c}1.53 \pm 0.23 \\
(1-2)\end{array}$ \\
\hline $3^{\text {rd }} 1$. larva & $\begin{array}{c}3.9 \pm 0.96 \\
(3.5-4)\end{array}$ & $\begin{array}{c}2.17 \pm 0.77 \\
(2-3)\end{array}$ & $\begin{array}{c}2.13 \pm 0.36 \\
(2-2.5)\end{array}$ & $\begin{array}{c}1.67 \pm 0.52 \\
(1-2)\end{array}$ \\
\hline $4^{\text {th }} 1$. larva & $\begin{array}{c}4.20 \pm 0.91 \\
(4-5)\end{array}$ & $\begin{array}{c}3.37 \pm 0.22 \\
(3-4)\end{array}$ & $\begin{array}{c}3.26 \pm 0.76 \\
(2.5-3.5)\end{array}$ & $\begin{array}{c}1.93 \pm 0.54 \\
(1-2)\end{array}$ \\
\hline Pre-pupa & $\begin{array}{c}2.9 \pm 0.76 \\
(2.5-3)\end{array}$ & $\begin{array}{c}2.13 \pm 0.33 \\
(1-2.5)\end{array}$ & $\begin{array}{c}1.47 \pm 0.19 \\
(1-2)\end{array}$ & $\begin{array}{c}1.06 \pm 0.11 \\
(1-1.5)\end{array}$ \\
\hline Pupa & $\begin{array}{c}9.8 \pm 1.7 \\
(8-10)\end{array}$ & $\begin{array}{c}6.0 \pm 1.3 \\
(5-7)\end{array}$ & $\begin{array}{c}4.61 \pm 0.96 \\
(4-6)\end{array}$ & $\begin{array}{c}3.27 \pm 0.63 \\
(2-3.5)\end{array}$ \\
\hline
\end{tabular}




\begin{tabular}{|c||c||c|c||c||}
\hline Total life cycle & $29.1 \pm 1.7$ & $19.6 \pm 1.71$ & $16.91 \pm 1.11$ & $11.1 \pm 1.71$ \\
& $(24-32)$ & $(16-24)$ & $(14-19)$ & $(7-12)$ \\
\hline
\end{tabular}

15 replicates used.

Table 3. Duration (days + SE) of immature stages of Bracon hebetor reared on Plodia interpunctella at different temperatures.

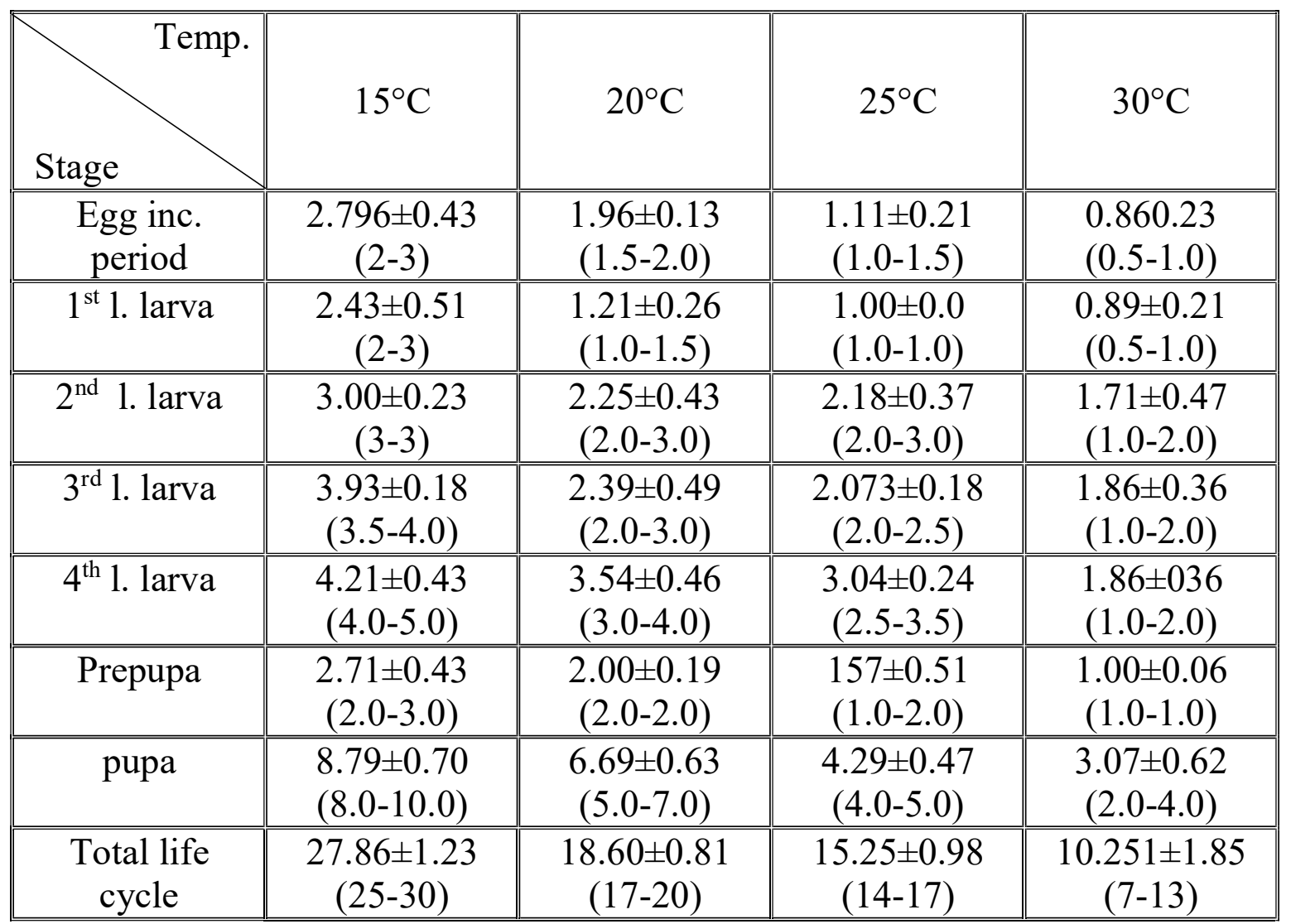

Table 4. Longevity (days+SE) of both sexes Bracon hebetor reared on Cadra cautella and fed on bee honey at different temperatures.

\begin{tabular}{|c||c|c|}
\hline $\begin{array}{c}\text { Sex } \\
\text { Temp. }\end{array}$ & Female & Male \\
\hline \hline $15^{\circ} \mathrm{C}$ & $77.71 \pm 2.76(67-86)$ & $28.76 \pm 4.91(25-31)$ \\
\hline $20^{\circ} \mathrm{C}$ & $59.57 \pm 2.01(58-62)$ & $11.43 \pm 1.66(9-14)$ \\
\hline $25^{\circ} \mathrm{C}$ & $43.86 \pm 2.78(40-46)$ & $7.57 \pm 1.24(7-9)$ \\
\hline \hline $30^{\circ} \mathrm{C}$ & $17.83 \pm 1.32(17-19)$ & $4.73 \pm 1.63(4-5)$ \\
\hline
\end{tabular}


Table 5: Duration (days+SE) of Pre-, oviposotion, post-oviposition periods, fecundity and total number of eggs per female Bracon hebetor parasitizing Cadra cautella at different temperatures.

\begin{tabular}{|c|c|c|c|c|c|}
\hline Period & Pre-ov. P. & $\begin{array}{l}\text { Oviposition } \\
\text { period }\end{array}$ & Post-ov.p. & $\begin{array}{c}\text { Fecundity } \\
\text { (eggs/female } \\
\text { /day) }\end{array}$ & $\begin{array}{l}\text { Total no. } \\
\text { eggs/female }\end{array}$ \\
\hline $15^{\circ} \mathrm{C}$ & $\begin{array}{c}4.25 \pm 0.50 \\
(4-5)\end{array}$ & $\begin{array}{c}72.25 \pm 6.39 \\
(65-79)\end{array}$ & $\begin{array}{c}7.75 \pm 3.5 \\
(4-12)\end{array}$ & $\begin{array}{c}1.69 \pm 0.5 \\
(1-2)\end{array}$ & $\begin{array}{c}122.0 \pm 5379 \\
(113-129)\end{array}$ \\
\hline $20^{\circ} \mathrm{C}$ & $\begin{array}{c}1.75 \pm 0.5 \\
(1-2)\end{array}$ & $\begin{array}{c}56.75 \pm 1.5 \\
(56-59)\end{array}$ & $\begin{array}{c}3.50 \pm 1.73 \\
(20-50)\end{array}$ & $\begin{array}{c}5.35 \pm 0.9 \\
(5-7)\end{array}$ & $\begin{array}{c}300.0 \pm 11.14 \\
(224-315)\end{array}$ \\
\hline $25^{\circ} \mathrm{C}$ & $\begin{array}{l}0.75 \pm 0.5 \\
(0.0-1.0)\end{array}$ & $\begin{array}{c}41.25 \pm 1.5 \\
(40-43)\end{array}$ & $\begin{array}{c}3.0 \pm 1.41 \\
(2-5)\end{array}$ & $\begin{array}{c}7.97 \pm 1.1 \\
(7-9)\end{array}$ & $\begin{array}{c}327.5 \pm 14.72 \\
(317-338)\end{array}$ \\
\hline $30^{\circ} \mathrm{C}$ & $\begin{array}{c}0.0 \\
(0.0-0.0)\end{array}$ & $\begin{array}{c}18.00 \pm 0.81 \\
(17-10)\end{array}$ & $\begin{array}{c}0.50 \\
(0.0-1.0)\end{array}$ & $\begin{array}{c}14.05 \pm 2.7 \\
(12-15)\end{array}$ & $\begin{array}{c}253.00 \pm 9.01 \\
(241-260)\end{array}$ \\
\hline
\end{tabular}

